Pecvnia, 10 (2010), pp. 75-94

\title{
Aproximación crítica a la crisis económica mundial: Sistema capitalista, política monetaria y globalización financiera
}

Recibido: Abril 2010

Aceptado: Mayo 2010

\author{
Fernando J. García Quero \\ fgquero@ugr.es
}

Universidad de Granada

Fac. de Ciencias Económicas y Empresariales Campus Univ. de La Cartuja 18071 Granada (España)
Para comprender las verdaderas causas de la crisis económica mundial en la que aún estamos inmersos, es necesario abordarla dentro del proceso de integración del sistema financiero internacional, entendido como la evolución del régimen económico capitalista contemporáneo. El presente trabajo analiza la crisis actual desde esa perspectiva, mostrándola como una causa directa al modelo de expansión capitalista cuyos inicios se remontan a la década de los 70 . Esta orientación nos ayudará a vislumbrar otra serie de problemas fuera de la esfera financiera e inherentes al modelo de crecimiento de los últimos 30 años.

Palabras clave: crisis económica mundial, sistema capitalista, globalización financiera, política monetaria, desarrollo económico.
This paper aims to analyse the true causes of the current global economic crisis. In order to get a good understanding of the problem, this crisis needs to be considered as a consequence of the integration of the international financial system, the last evolution of the contemporary capitalist regime. By dealing with the subject in this way, it becomes possible to discern new problems, which are inherent in the capitalist model of expansion which began 30 years ago, known as post-fordism.

Key words: global economic crisis, capitalist system, financial globalization, monetary policy, economic development. 


\section{INTRODUCCIÓN}

Hace ya cuatro años que el sistema económico internacional entró en una fase de desaceleración. En un principio todo parecía apuntar al shock bursátil más severo desde la Gran Depresión ${ }^{1}$ como principal responsable de la situación que se avecinaba. Incluso las previsiones más optimistas, advirtieron que no se emprendería una recuperación moderada hasta finales del 2010 (FMI 2008). El epicentro de la recesión se localizó en EE.UU. en $2006^{2}$, pero sus efectos se fueron extendiendo al resto de las economías del mundo, poniendo en riesgo a la totalidad del entramado financiero internacional.

Tal orden de sucesos invita a reflexionar sobre una cuestión capital: ¿Cómo fue posible una propagación tan rápida y virulenta de la crisis, hasta afectar a todas las economías? Esta interrogación conduce a nuevas incógnitas, a saber: ¿Han existido otras crisis de naturaleza financiera durante la última fase de expansión capitalista que justifiquen en cierta medida esta propagación?, ¿Cómo una situación específica de un mercado concreto puede provocar una depresión de tal magnitud? El propósito de este trabajo es dar respuesta a estas cuestiones, mediante una aproximación crítica respecto al problemático funcionamiento del sistema financiero y al cambio de modelo de acumulación producido en el último tercio del siglo XX.

A la hora de responder a estos interrogantes nos planteamos si las transformaciones sufridas en el sistema capitalista mundial, durante las tres últimas décadas del pasado siglo, originaron un desgaje progresivo de su ámbito financiero que posteriormente propició la gestación de la llamada Globalización Financiera ${ }^{3}$. Es también preciso preguntarnos si la

Así lo advirtieron unas declaraciones del presidente del Banco Central Europeo (BCE), Jean Claude Trichet: "La actual crisis es la mayor desde la Segunda Guerra Mundial, con un nivel de incertidumbre absolutamente excepciona"; "Nada en el pasado se parece a lo que vemos actualmente" (declaraciones hechas a la cadena France 24 y expuestas en el diario digital El economista el 02/10/2008).

2 Concretamente en las distorsiones ocasionadas en el mercado hipotecario norteamericano, que salieron a la luz con el estallido de la burbuja inmobiliaria en 2006 (FMI, BM, Cumbre G-20). Se denomina burbuja inmobiliaria al incremento de los precios de la vivienda por encima de la evolución normal de los precios de los activos, reflejada en el IPC (Índice de Precios al Consumo), es resultado de una corriente especulativa en el mercado de la vivienda.

3 Hace referencia al nombre que se le atribuyen a las transformaciones que han afectado a los principios de funcionamiento de las finanzas y a su integración a nivel mundial (Aglietta 2000). 
expansión de esta Globalización Financiera nos han conducido hasta la situación actual en la que nos encontramos inmersos: la crisis financiera mundial.

Para interpretar estos hechos nos situaremos en el enfoque endógeno del dinero, lo que nos ayudará a comprender las diferentes dimensiones que hacen de la globalización financiera un fenómeno complejo. Partiendo de este enfoque, analizaremos las trasformaciones que ha sufrido el sistema capitalista desde la finalización de la II Guerra Mundial, identificando dos periodos muy distintos, tanto en la regulación monetaria, como en la orientación del capitalismo, de cara a comprender los cambios producidos tras los años 70 que propiciaron un nuevo periodo de expansión capitalista regido por las finanzas internacionales (Globalización Financiera). Este nuevo periodo a través de sus mecanismos de expansión crea una red de flujos financieros inestables que explicaremos vinculándolos a las políticas económicas que los han potenciado. De este modo la crisis financiera mundial se mostrará como una consecuencia palpable del proceso desenfrenado e irregulado de la Globalización Financiera.

\section{TEORÍA ENDÓGENA DEL DINERO: DIMENSIONES DEL SISTEMA}

\section{FINANCIERO}

Para abordar y analizar el proceso de Globalización Financiera en curso, es preciso clarificar el significado teórico y práctico del dinero y las finanzas. En la historia del pensamiento económico se han planteado dos grandes líneas interpretativas del papel del dinero y las finanzas (González Tablas y Medialdea 2001). La primera, que se puede denominar Principio Monetario, viene avalada por la corriente monetarista liderada por el economista Milton Friedman, premio Nobel de Economía en 1976 y principal investigador de la Escuela de Chicago. Esta orientación se caracteriza por el presupuesto teórico de que la oferta de dinero es una variable exógena a la economía real, controlable exclusivamente por el Banco Central, y de que el sector monetario no influye internamente en la economía real, sino que se introduce posteriormente bajo el único fin de controlar los precios (Friedman 1992). La segunda, denominada Enfoque endógeno del dinero, tiene una más larga trayectoria teórica, puesto que se inicia con autores clásicos como John Stuart Mill o Karl Marx, llega hasta John Maynard Keynes y se prolonga a través de sus seguidores más 
heterodoxos ${ }^{4}$. Para este enfoque, el dinero es una categoría propia de la naturaleza y el funcionamiento de la economía real. La oferta de dinero está directamente condicionada por el criterio maximizador de beneficios que rige toda la actividad económica capitalista, siendo propia a su funcionamiento.

En este artículo se asume que la oferta de dinero, como sostiene el enfoque precitado, es endógena y responde al principio de la maximización del beneficio que rige el modelo de acumulación capitalista. Desde esta perspectiva, se entiende que la visión monetarista es muy restrictiva, dado que considera al dinero como simple instrumento, puramente técnico, facilitador del intercambio y cuyo contenido es únicamente material (González Tablas y Medialdea 2001). Es por ello que no consideramos adecuada la orientación monetarista a la hora de explicar el comportamiento de la economía actual, ni la recesión en la que nos encontramos. Sin embargo en la orientación endógena de las finanzas, se incorpora una dimensión histórica, social e institucional al análisis, lo que nos permitirá entender más adecuadamente el papel que ha desempeñado la integración financiera internacional sobre la crisis actual. Como subrayan los teóricos de la escuela francesa de la Regulación, los flujos financieros son vínculos sociales e instituciones ligadas a la soberanía ${ }^{5}$.

El afrontar nuestro análisis de la recesión actual a través de una perspectiva endógena nos permite, a pesar de que la crisis actual se focaliza en el sistema financiero, interpretarla desde una perspectiva más global, entendiéndola más allá de lo estrictamente monetario, como una consecuencia directa del modelo de expansión capitalista contemporáneo. Esta forma de abordar nuestro estudio nos requiere realizar un análisis de la evolución que ha sufrido el sistema capitalista para poder comprender el funcionamiento del actual sistema financiero.

En las páginas que siguen exploraremos el modelo de acumulación que surge tras el final de la II Guerra Mundial y el papel que las finanzas y la moneda toman en su desarrollo. Para los teóricos de la regulación, el periodo estudiado se corresponde con una fase en la que denomina el dinero politizado, caracterizada por una regulación monetaria

\footnotetext{
4 Para profundizar sobre los principios del enfoque endógeno ver la obra maestra de Keynes (1948) Teoría general del empleo, el interés y el dinero. México, D.F.: Fondo de Cultura de México.

5 Ver Michael Aglietta y Jean Carletier (2002) "Orden monetario de las economías de mercado", Cuadernos de Economía, XXI, 36, Bogotá, pp. 41-75.
} 
por parte de los Bancos Centrales, a instancias de los gobiernos; y un sistema de cambios mundial sustentado en el patrón dólar.

\section{MODELO DE ACUMULACIÓN FORDISTA Y DINERO POLITIZADO}

A pesar de que el modelo de desarrollo capitalista actual tiene su origen en los años 70, la mejor manera de facilitar su comprensión es conocer cuales son sus antecedentes. A comienzos del siglo XX, el modelo de crecimiento capitalista se vio influenciado paulatinamente por un nuevo modelo productivo, conocido como fordista ${ }^{6}$. Esta nueva forma de producción se impuso en los países industrializados, permitiendo a sus industrias alcanzar un gran crecimiento. Después de la Segunda Guerra Mundial, con la entrada en la esfera internacional de la influencia de las políticas económicas Keynesianas, se constituyó el ambiente idóneo para la consolidación del fordismo como modo de ordenación de las relaciones sociales (Piñero 2004). Este giro influyó en los principales actores del modelo capitalista: el Estado asumió nuevos roles y el capital tuvo que ajustarse a normas y regulaciones para asegurar la estabilidad financiera (Harvey 1998).

Uno de los principales pilares en la expansión de este nuevo modelo de crecimiento capitalista fue el papel que tomó el capital. Por primera vez, se estableció una regulación internacional a nivel financiero (el Sistema de Bretton Woods ${ }^{7}$ ), que limitó en gran medida el rol del dinero. Este modelo de regulación financiera transformó por completo las relaciones monetarias internacionales, que comenzaron a articularse en torno a un tipo de cambio fijo respecto al dólar ${ }^{8}$. No debemos olvidar que EE.UU. fue el máximo beneficiado de dicha cita, no sólo se consolidó

6 Recibe su nombre debido a su inventor Henry Ford, se fundamenta en la aplicación de un nuevo modelo productivo basado en la cadena de montaje en serie, donde los operarios ensamblaban piezas que eran transportadas en cintas con movimiento continuo (Gramsci 1973).

7 Durante el verano 1944, 44 países se congregaron en la ciudad estadounidense de Bretton Woods con motivo de la "Conferencia Monetaria y Financiera de las Naciones Unidas". El máximo objetivo de la reunión era establecer las bases para el funcionamiento de un sistema monetario común a nivel internacional. La complejidad y dimensión del mercado financiero y las desastrosas experiencias acaecidas durante el periodo de entreguerras, demandaban una intervención urgente para establecer una regulación internacional consonante a nivel monetario (Lichtensztejn y Baer 1986; Deutsch 1974).

Se estableció una paridad entre oro y dólares. EE.UU. asumía el compromiso de mantener el precio del oro en 35 dólares por onza. El resto de países tenían la obligación de fijar el precio de sus monedas en relación al dólar, estableciéndose un máximo del $1 \%$ para las fluctuaciones en el tipo de cambio de sus monedas (Deutsch 1974). 
como máximo líder mundial, sino que también obtuvo importantes ventajas ${ }^{9}$ respecto al resto de países (Arrighi 1998; Aglietta 2000). Los compromisos adoptados en Bretton Woods, condicionaron en gran medida el funcionamiento del sistema económico capitalista al transformar la función del dinero. El capital pasó a ser un instrumento secundario de política económica y se supeditó a otras funciones del Estado, gasto social, inversiones productivas. Estos hechos se conocen como politización de las finanzas (Aglietta 2000).

Las nuevas posibilidades que brindaba el capital, al servicio de la política, facilitaron el desarrollo de la política económica keynesiana, que potenció el impulso del Estado del Bienestar ${ }^{10}$. Las políticas estatales se destinaron a garantizar el crecimiento de la producción y del consumo en masa, disminuir la tasa de desempleo, fortalecer el crecimiento de los salarios, aumentar la dotación hacia las infraestructuras públicas, gastos en seguridad social, salud, educación y vivienda. La orientación del Estado no respondía a la lógica del máximo beneficio, sino que mediante una combinación de políticas fiscales y monetarias trataba de controlar los ciclos económicos, permitiendo conciliar un crecimiento económico estable con una mejora en las condiciones materiales de vida de la población (Piñero 2004). Este modelo de crecimiento capitalista, otorgaba un plano secundario al comercio internacional y al de capitales, por el contrario, el motor que lo estimulaba era la transformación interna de los procesos de producción, la economía se centra en el mercado interno a través del impulso de la demanda efectiva gracias al aumento en el poder adquisitivo de la población (Keynes 1948).

El modelo de crecimiento de posguerra estuvo fundamentado en el papel del Estado como organizador de la vida económica, los flujos financieros constituyeron una herramienta regulada y controlada por los

9 En Bretton Woods se crearon dos organismos internacionales el Fondo Monetario Internacional (FMI) y el Banco Mundial (BM). En el sistema de cuotas de participación en el FMI que establece el poder de votación y control del organismo (EE.UU. logró el mayor número, obteniendo capacidad de veto sobre cualquier decisión). Para el BM, se estableció un mecanismo de suscripción al mismo, que igualmente otorgó la máxima capacidad de decisión a EE.UU. En cuanto a la localización territorial, ambos organismos se asentaron en suelo estadounidense (Rajamoorthy 2004).

En lo referente al sistema monetario, en la práctica el dólar pasó a ser la moneda internacional, a pesar de su paridad con el oro, lo que obligó a todos los países a acumular reservas de dólares para hacer frente a las fluctuaciones de sus respectivas monedas. Este sistema dotó a EE.UU. de un privilegio exorbitante en materia de pagos internacionales frente al resto de países, que en los hechos sirvió para que éstos financiaran el déficit presupuestario norteamericano (Rajamoorthy 2004).

10 Se refiere al desarrollo de políticas que buscan como objetivo principal la mejora de la protección social de las personas (sanidad, educación, derechos laborales, etc.). 
gobiernos, al servicio de la política y cuya máxima función estribaba en potenciar un modelo de crecimiento productivo. A grandes rasgos éstas fueron las características principales del modelo de crecimiento capitalista que se sostuvo hasta principios de la década de los $70^{11}$, y permitió un crecimiento sin precedentes a escala mundial ${ }^{12}$.

\section{FIN DE UN MODELO DE ACUMULACIÓN Y DESPOLITIZACIÓN}

\section{DE LA MONEDA}

Durante las décadas de los 50 y 60 , el desarrollo económico fue aumentando vigorosamente, hasta alcanzar niveles sin precedentes en la historia del capitalismo, lo que dificultó contener una expansión desenfrenada del capital. Esta situación ocasionó que cada vez fuera más complejo, para el modelo de desarrollo económico, canalizar los flujos de capital hacia la inversión productiva, lo que acarreó dos consecuencias: por una parte, el modelo de acumulación fordista-Keynesiano pasó a ser un obstáculo para el proceso de expansión del capital, y por otra, la legitimidad del Estado fue minándose gradualmente, al acrecentarse un nivel general de insatisfacción, justificado ante las enormes dificultades para ampliar los beneficios del fordismo a toda la sociedad (Lichtensztejn y Baer 1986).

A finales de los 60 , estos hechos se vieron acompañados de un clima de inestabilidad en los mercados monetarios internacionales, las emisiones continuas de moneda por parte de EE.UU. para financiar sus problemas fiscales, propició una pérdida de confianza en el dólar como moneda reserva internacional estable. A estos sucesos se les sumaron graves procesos inflacionarios que cada vez hacían más insostenible seguir manteniendo los acuerdos pactados en Bretton Woods. Estas presiones hicieron que los límites al capital acordados 27 años antes se vieran desbordados por completo, al punto que el 15 de agosto de 1971 el gobierno del por entonces presidente norteamericano Richard Nixon puso

11 Tenemos que aclarar que la expansión internacional del fordismo aconteció de manera desigual en los diferentes países, en tanto que cada Estado intentaba crear su propio modo de gestionar las relaciones del trabajo, la política fiscal y monetaria, la inversión pública y las estrategias de bienestar social.

Simultáneamente los EE.UU. se tornaron hegemónicos por medio de tres vías: cultural (exportación del modelo de vida americano); financiarización, por medio del Plan Marshall; institucionalmente gracias a acuerdos como el de Bretton Woods y la creación de organismos internacionales como el FMI, BM o el GATT (Piñero 2004).

12 Este periodo de tiempo (1945-1973) se conoce como "los Treinta gloriosos". 
fin a la convertibilidad del dólar con el oro, acabando así con el sistema de Bretton Woods vigente desde 1944. Con esta medida se produjo la desmaterialización por completo de la obligación monetaria de los países a ingresar una cuota determinada en la institución responsable del oro, al mismo tiempo se acabó con las barreras impuestas a la expansión internacional desenfrenada de los flujos financieros y a los controles sobre los movimientos de capital.

A partir de ese momento dejó de existir una relación directa entre el valor de cada moneda y las reservas nacionales de una mercancía con valor intrínseco propio, el oro. El abandono de un sistema basado en unos tipos de cambio fijos, junto con la finalización del control sobre los movimientos de capital, originaron el surgimiento de un sistema financiero enormemente desregulado, más descentralizado y coordinado únicamente por el mercado, que otorgaba rienda suelta a la liberalización de los mercados de capitales (Amin 1998; Chesnais 2002), lo que propició unas condiciones financieras mucho más volátiles e inestables (Aglietta 2000; Arrighi 1998).

A finales de 1973, la economía mundial entró en años de recesión generalizada (Crisis del Petróleo) ${ }^{13}$ : tasas de inflación y desempleo desmesuradas, descenso de la producción industrial, caídas pronunciadas en los ingresos nacionales, o aumentos sin precedentes de los déficit en las balanzas de pagos son sólo algunos de los problemas a los que tuvieron que hacer frente multitud de países (Angélopoulos 1979). A pesar de la crudeza de las cifras, lo que verdaderamente marcaría el futuro, no fue la crisis, sino el fin del modelo capitalista de acumulación dirigido hacia el consumo de masas, que dejó paso a una nueva fase de expansión del sistema capitalista mundial, cuya semilla, como hemos visto, llevaba germinándose desde unos años antes. El nuevo paradigma en el sistema de producción (posfordismo ${ }^{14}$ ), se fundamentaba bajo una producción y distribución flexibles y la entrada del lenguaje en la esfera productiva (Marazzi 2003). La saturación de los mercados internos debido a la intensificación de la competencia internacional hizo necesario la

13 Recibe este apelativo ya que para muchos fue el aumento en el precio del crudo la causa principal de los sucesos acaecidos. El 17 de octubre de 1973 los países exportadores de petróleo decidieron no exportar más crudo a los países que habían apoyado a Israel durante la guerra del Yom Kippur, entre los que se encontraban EE.UU. y sus aliados europeos. Este embargo hacia las exportaciones de petróleo cuadriplicó su precio en menos de un año (Deutsch 1974).

14 Los orígenes del posfordismo se remontan a Japón en el año 1950, para ser concretos a los talleres de la empresa Toyota (Marazzi 2003). 
consolidación de una nueva orientación económica que diera pasó de la manufacturación de bienes a la fabricación de ideas, y al tratamiento de la información, no del personal ni de las existencias (Arrighi 2000; Stiglitz $2003)^{15}$. Las innovaciones en las tecnologías de la información y la entrada de la comunicación en la esfera productiva permitieron a las empresas ejercer un control en tiempo real de sus existencias (Marazzi 2003).

Todas estas transformaciones se vieron afianzadas por el brusco cambio en la orientación de las políticas estatales que supuso la aparición en la escena internacional de los gobiernos conservadores de Margaret Thatcher en Inglaterra (1979-1990) y de Ronald Reagan en EE.UU. (1981-1989). De su mano vino la consolidación de una nueva orientación económica, asentada en la Teoría Económica Neoclásica ${ }^{16}$, que a la vez que afianzó el fin a la regulación en los movimientos de capitales, incentivó la iniciativa privada e introdujo mecanismos de mercado en la esfera pública. Estas medidas fueron posibles mediante el fortalecimiento de un tipo específico de políticas, que presentaban las mismas características, en el mayor número de países posible: reducción de las actividades gubernamentales y racionalización de la gestión de los servicios públicos (disminución gasto público), control de grupos de presión (especialmente los sindicatos), tasas de interés elevadas, desmantelamiento de las políticas de pleno empleo, desgravaciones fiscales en beneficio de las personas con un riqueza más alta (Brugue 1992; Huguet 2005; Amin 2001).

En cuanto al papel del Estado, dejó de estar orientado al ciudadano y a las prioridades públicas para hacerlo al consumidor y la "gestión eficiente"17 (Brugue 1992). Uno de los temas que más enfrentamientos produjo fue la legislación fiscal en materia impositiva, orientada hacia la reducción del gasto público en materia social y la carga impositiva, especialmente de los sectores de la sociedad con mayores

15 La industria manufacturera disminuyó hasta representar no más del $14 \%$ de la producción total y un porcentaje aún menor de la población activa.

16 Esta teoría se fundamenta sobre la tradición liberal clásica, principalmente en Adam Smith y su famosa teoría de la mano invisible (Smith 1996), para recuperar la confianza en el mercado, proclamando la desregulación de la economía y autorregulación de los mercados.

17 Las medidas más comunes fueron: privatizaciones de propiedades públicas, relajación monopolios estatales, reducción subsidios, incremento tarifas servicios públicos..., es decir, políticas enfocadas a reforzar la confianza en el mercado. Un claro ejemplo fue la ley Compulsory Competitive Tendering, aprobada en Inglaterra en 1987, y que obligaba a las administraciones locales a someter a concurso público muchos de sus servicios (limpieza, mantenimiento, comidas escolares, etc.) (Brugue 1992). 
ingresos (Brugue 1992) ${ }^{18}$. Esta visión a favor del minimalismo de Estado (Hayek 2006) es catalogada por Joseph Stiglitz como fundamentalismo de mercado, calificándola de ideología al considerarla más una cuestión de fe que un razonamiento empírico: sostener que los mercados son estables y eficientes por sí mismos, no se basa en ninguna teoría económica aceptable y se contradice con innumerables experiencias (Stiglitz 2003: 60; 438).

A nivel financiero, la política monetaria dejó de ser una herramienta de uso estatal potenciadora de inversiones en capital productivo, a ser una herramienta en manos de una autoridad monetaria independiente de los gobiernos (los bancos centrales y la reserva federal norteamericana) que fortaleció los intereses privados de grandes multinacionales y corporaciones financieras (Arrighi 1998). Estos cambios que dotaron a la expansión financiera de un carácter autosuficiente, responden al calificativo de despolitización de las finanzas (Arrighi 1998). La lógica de funcionamiento en la que se basa prima el beneficio exclusivo del capital financiero (Aglietta 2000; Aglietta y Cartelier 2002; Amin 2001) e impera en favor de las grandes corporaciones financieras y de los mercados de capitales (Bhagwati 2005; Stiglitz 2003).

Las transformaciones fueron significativas, todos los países industrializados aumentaron su desregulación económica, las reformas tributarias, las privatizaciones y la flexibilidad laboral, propiciando unos logros significativos a corto plazo (tasas de crecimiento continuadas, reducción de la inflación), aunque lo cierto es que a medio y largo plazo, como veremos en el apartado siguiente, se fomentó una economía efímera e inestable (Aglietta 2000; Aglietta y Cartelier 2002; Arrighi 2000; Stiglitz 2003; González Tablas y Medialdea 2001; Kindleberger 1991; Galbraith 1991), que se ha extendido hasta nuestros días, como muestran los hechos que están aconteciendo durante los últimos años.

En resumen, la expansión de las políticas económicas neoclásicas, junto con la influencia de los cambios producidos en el modelo de acumulación (posfordismo) y la transformación en el régimen de regulación monetaria internacional (despolitización de la economía), favorecieron una espiral creciente de expansión en las finanzas que fue

18 La ley de finanzas aprobada en 1988 en Inglaterra, conocida vulgarmente como Poll Tax, suprimió el sistema tributario existente, eliminando los componentes regresivos del mismo, por tanto, se favoreció a las personas con mayores ingresos en detrimento del resto. Al disminuir considerablemente la carga fiscal de las rentas más altas y aumentar la de los que tenían menores ingresos (Brugue 1992). 
fortaleciendo paulatinamente una Globalización Financiera sin control y desvinculada de toda regulación.

\section{LA FASE DE FINANCIARIZACIÓN DE LA ECONOMÍA: EL GERMEN DE LA CRISIS}

Pese a que el concepto Globalización parece sugerir un fenómeno novedoso, para la escuela del sistema-mundo ${ }^{19}$ tal novedad no se corresponde con la realidad si se analiza la evolución del capitalismo en perspectiva histórica, por el contrario, tiene lugar desde que el ser humano ha sido capaz de trasladarse a lo ancho y largo del planeta (Arrighi 1998; Braudel 1986; Wallerstein 1995). La globalización como tal, no ha variado, lo que si lo ha hecho, es el sistema económico y social en el que ha tenido lugar. Por tanto, cada proceso globalizador ha estado directamente supeditado a la lógica del sistema en el que se encontraba inmerso, el cuál ha condicionado tanto su interacción como los efectos del mismo (Amin 2001). En este sentido, la Globalización actual está ligada al sistema capitalista contemporáneo, cuyo surgimiento, como se ha visto en el apartado anterior, se sitúa a partir de los años 70 (Amin 2001; Stiglitz 2004). La peculiaridad de esta nueva globalización estriba en tres aspectos: su estrecha relación con un ámbito diferente del sistema capitalista, las finanzas (Aglietta 2000; Arrighi 1998, 2000); su influencia sobre las condiciones de crecimiento de las economías, y la tremenda inestabilidad que le es natural y que alimenta crisis financieras periódicas (Aglietta 2000). Por todas estas cuestiones este régimen financiero ha recibido la etiqueta de Globalización Financiera (Arrighi 1998).

La argumentación anterior nos lleva a la imposibilidad de entender la Globalización Financiera sin comprender, que las finanzas se engloban dentro de un proceso económico más general, el sistema económico capitalista. Este hecho, es el que nos ha obligado a realizar un estudio minucioso de la transformación en la que se vio envuelto el régimen capitalista durante los años 70 , cuyo resultado, nos sirve de base para comprender el despegue y la posterior expansión del proceso de Globalización Financiera.

19 Inmanuele Wallerstein $(1995,1999)$ es el máximo representante de esta escuela de pensamiento; la teoría del sistema-mundo se centra en el estudio del sistema social y sus interrelaciones con el avance del capitalismo mundial. 
Aproximación crítica a la crisis económica mundial: Sistema capitalista, política monetaria y globalización financiera

La evolución de la Globalización financiera durante los últimos treinta años, apoyada bajo el nuevo modelo de expansión capitalista, como hemos comprobado anteriormente, originó un cambio paulatino en el tratamiento que hasta el momento se le había otorgado a las finanzas. Éstas, pasaron a imperar sin oposición, buscando el beneficio fortaleciendo su carácter especulativo frente al productivo (Stiglitz 2004). En ocasiones se han catalogado estos aspectos con la expresión de ensimismamiento financiero, el ámbito del capital se hace autónomo, pareciendo como si contase con un motor y unos criterios de funcionamiento propios (González Tablas y Medialdea 2001). Este nuevo rumbo en materia financiera se caracteriza por la paradoja de que no hace falta ser más productivo para obtener beneficios, sino que es suficiente con jugar en los mercados bursátiles comprando y vendiendo divisas, cosechas a futuro o derechos sobre hipotecas de dudoso riesgo, para conseguirlo (Bourdieu 1998, 2002).

Esta disposición hacia la financiarización ha provocado un aumento de la demanda de riqueza financiera, es decir, el acceso a los mercados financieros se ha generalizado a un número mucho más amplio de agentes (particulares, familias, instituciones), tanto demandantes de activos financieros, como intermediarios (González Tablas y Medialdea 2001). Por otra parte, a los productos financieros tradicionales se les han ido uniendo otra serie de posibilidades de obtener ganancias en los mercados bursátiles (Aglietta 2000).

Estos sucesos se ven acompañados de una nueva lógica de funcionamiento en los mercados financieros, no podemos olvidar que cada vez son más los agentes que conviven en al ámbito financiero y tienen unos objetivos concretos, priorizar a toda costa el aumento de los valores bursátiles sin preocuparse por las consecuencias futuras (Aglietta 2000; Stiglitz 2003). El lapso temporal en el que estas transformaciones han tenido lugar ha sido muy reducido y de forma ineludible se han ido expandiendo hacia múltiples países, propiciando que aumentara la interdependencia financiera mundial, lo que ha provocado que cada vez más, los fenómenos recesivos, como la presente crisis, afecten por igual a diferentes economías, independientemente de cual sea el motivo concreto de su estallido.

En cuanto a la expansión de este modelo de crecimiento a nivel mundial, ha sido posible gracias a una homogenización paulatina en las políticas económicas y en las conductas llevadas a cabo en los países con economías más avanzadas, las cuales se han ido extrapolando al resto 
de países (Chesnais 2002; Chesnais y Phil 2003). Con este fin, se ha puesto en práctica una profunda ola de medidas $^{20}$ por parte de grandes corporaciones internacionales y en especial por organismos internacionales (FMI, BM) encaminadas a favorecer, por encima de todo, la lógica de los intereses de las élites financieras, lo que ha propiciado un crecimiento turbulento y ficticio y desigual en todas partes del mundo (Krugman 2004). Estas políticas y comportamiento se han basado en los siguientes principios: desregulación y liberalización, contabilidad engañosa, incentivos a la especulación y política monetaria estéril y desaprensiva (Stiglitz 2003); lo que explica en gran medida el por qué de la inestabilidad endémica que acompaña a la Globalización Financiera y que ha desembocado en una crisis de calado mundial.

Para comprender la espiral de crisis financieras que ha sido inherente a la expansión de modelo de crecimiento capitalista surgido a partir de los años 70, y al mismo tiempo vislumbrar las características que hacen diferente a la recesión actual, presentaremos de modo desarrollado las medidas, mencionadas anteriormente, que han acompañado a la Globalización Financiera en su proceso de expansión mundial y como éstas han afectado a la economía actual:

- Desregulación y liberalización: estas políticas han sido posibles debido a la omisión del papel regulador del Estado, olvidando que la regulación ayuda a mitigar conflictos de intereses y práctica abusivas (Stiglitz 2003). Las desregulaciones han estado principalmente vinculadas al sector bancario, donde se han cometido muchos excesos. Los bancos han pasado de ejercer una función de control sobre la actividad empresarial (vigilancia cartera de créditos, préstamos, asegurar la garantía de sus devoluciones) a tener las manos libres para realizar cualquier tipo de operación, embarcándose en operaciones de gran riesgo. Las transformaciones en la banca norteamericana han influido muy claramente en el desarrollo de la economía global (Torres 2005). Otros sectores a los que ha ido afectando el torbellino desregulador fueron las telecomunicaciones, las finanzas y las compañías eléctricas.

- Contabilidad obsoleta e información engañosa: las deficiencias en los sistemas de contabilidad han facilitado la posibilidad

20 El Consenso de Washington ha sido el máximo exponente de la exportación de estas políticas a los países con economías menos desarrolladas. Para un análisis más riguroso ver Chang 2004. 
de que muchas empresas arrojaran datos erróneos sobre su realidad ${ }^{21}$, este hecho ayuda a explicar, al menos parcialmente la exuberancia irracional de las cifras. La actividad de los contables en muchas ocasiones se ha dirigido a intentar mejorar el aspecto de la situación financiera real de las empresas, ocultando irregularidades en sus balances y en la situación de sus activos (Stiglitz 2003). Las consecuencias de estos actos son claras, mostrar una imagen de la empresa que no se corresponde con la realidad, reflejando una posición engañosa de la misma.

- Incentivos a la especulación: políticas fiscales que han beneficiado a las operaciones especulativas, como las bajadas de los impuestos sobre las plusvalías. Esto ha propiciado que cada vez más agentes se vean incentivados a invertir en los mercados de capital.

- Política monetaria estéril: uno de los instrumentos más importantes para controlar la economía es la política monetaria, que es controlada por organismos independientes a los gobiernos, los Bancos Centrales (Reserva Federal Americana, Banco Central Europeo). La máxima preocupación de los bancos centrales es la lucha contra la inflación, sin importarles las repercusiones que sus políticas pueden tener para la economía (Torres 2005).

Como es de esperar, la consecuencia más directa de la lógica financiera presentada, es la creación de un crecimiento inadecuado que conlleva la aparición de crisis financieras de manera regular (Chesnais 2002). Muestra de ello, son la multitud de crisis financieras que se han vivido en todas las partes del globo durante las últimas dos décadas. En México la crisis de 1982, fue consecuencia del alza de las tasas en los tipos de interés norteamericanos; EE.UU. sufrió un duro revés en 1987 y en 1990; la totalidad de las economías de los mercados emergentes durante la segunda mitad de la década de los 90, México (1995), la mayoría de las economías asiáticas durante 1997 y 1998 (Corea, Indonesia, Tailandia, Malasia, Laos), poco después el pánico financiero se extendió al resto del mundo: Rusia 1998, Brasil 1999, Argentina 2001; convirtiéndose en una crisis de alcance mundial. Las únicas economías que escaparon a la crisis fueron India y China, las cuales se habían resistido a las medidas que se

21 El índice NASDAQ Composite, que agrupa en su mayoría valores tecnológicos, se elevo desde 500ptos en abril 1991 a 1.000 en julio 1995 , más de 2.000 en julio 1998 y valor máximo en marzo 2000, 5.132. Estas cifras no guardaban relación con el valor real de las empresas a las que se refieren (Stiglitz 2003: 49). 
les intentó imponer por parte del FMI para liberalizar sus economías en general y especial sus mercados de capitales (Chang 2004). La última crisis anterior a la actual, tuvo lugar durante 2002 y 2003 con el estallido de la burbuja tecnológica que había mantenido la economía norteamericana en un auge irreal (Stiglitz 2006). En medio de la crisis se debatió la necesidad de regular el sistema financiero con el fin de prevenir futuras recesiones, finalmente ninguna reforma importante tuvo lugar ${ }^{22}$. En agosto de 2007 el mercado bursátil norteamericano recibió un duro revés, lo que en poco tiempo desató una enorme crisis financiera mundial que a día de hoy continúa afectando a toda la economía.

Existen muchas teorías explicativas acerca de las causas que han producido los procesos de inestabilidad inherentes a la expansión internacional de la Globalización Financiera: problemas de información asimétrica (Stiglitz 2003); ciclos sistémicos de acumulación (Arrighi 1998); expectativas irracionales de los inversores (Kindleberger 1991); orgías especulativas (Galbraith 1991). Sin embargo, a la hora de comprender los verdaderos orígenes tanto de la ola de crisis periódicas que ha acompaña a la Globalización Financiera, como de recesiones específicas, ya sea la crisis de México en 1982, la del Este asiático, o la depresión que azota a la economía internacional desde hace cuatro años, ninguna de las teorías mencionadas anteriormente nos sirve de manera individual. El entramado financiero se ha vuelto tan complejo que cada vez son más las posibles causas de una recesión concreta. Hay que ir mucho más allá, de hechos aislados (subida en los tipos de interés, quiebra de una compañía de crédito, hipotecas basura o estallido de la burbuja inmobiliaria) para comprender la crisis económica en la que nos encontramos inmersos.

A pesar de que el origen inmediato de la depresión actual se encuentra en el mercado inmobiliario estadounidense, y su expansión mundial se ha debido a que los mercados de crédito internacionales se encuentran infectados por títulos hipotecarios impagables, las causas reales residen en cuestiones mucho más profundas relativas a irregularidades y fallos sistémicos que han hecho posible que ocurra una situación como en la que nos encontramos actualmente. De hecho este análisis se encamina a deducir que es imposible culpar a un hecho aislado de una economía concreta como único causante de la crisis actual. Estos fallos están presentes

22 Hubo algunos intentos por parte del FMI para idear otro modo de reestructurar la deuda (fue vetado por EE.UU.); la OCDE hizo una propuesta para restringir el secreto bancario (también fue vetado por EE.UU.) (Stiglitz 2003). 
en la orientación misma del sistema de crecimiento capitalista que sirve de base para la economía mundial. Por tanto, el verdadero problema de la crisis actual, es sistémico, y como hemos visto está en la naturaleza misma de nuestro modelo de crecimiento. Hemos argumentado que la Globalización Financiera no corresponde únicamente a la orientación del sistema financiero, sino que forma parte del proceso de expansión capitalista. Por tanto, no podemos simplificar las causas buscando errores en el sistema de regulación de las finanzas, porque aunque claro que los encontraremos, no servirán para solucionar la verdadera crisis, que se traduce en problemas no sólo de carácter financiero, sino que afectan directamente al bienestar e incrementan las desigualdades sociales.

\section{REFLEXIONES FINALES}

Hasta los años 70 las crisis del sistema capitalista eran consecuencias directas de aumentos en la producción por encima de las posibilidades de absorción del mercado, lo que ocasionaba resultados desastrosos, principalmente sobre la producción y el comercio. Por el contrario, la naturaleza de las crisis contemporáneas, es fruto de la transformación sufrida en el sistema capitalista durante el último cuarto de siglo, que se ha fundamentado bajo la expansión de unos mercados financieros globales y se ha legitimado bajo la economía neoclásica. Esta transformación de un capitalismo basado en la riqueza productiva a un capitalismo sustentado en la riqueza especulativa y auspiciado en las políticas de desregulación y liberalización de los flujos de capital características de los años 80 y 90 , queramos o no, está tremendamente relacionado con los fenómenos que estamos padeciendo. Se ha demostrado que las crisis financieras son una parte estructural del nuevo capitalismo, mundializado y privatizado en la esfera de las finanzas. La peculiaridad real de la depresión actual respecto a otras crisis financieras (México, Brasil, Rusia, etc.) acaecidas durante este ciclo de expansión capitalista, es que por primera vez ha afectado a los países más avanzados económicamente. Estas otras crisis pusieron de manifiesto muchos de los errores que se estaban cometiendo (relajación en los controles, incentivos al capital especulativo, etc.) y aún así nada se hizo para remediarlos.

El sistema financiero internacional, independientemente de la opinión que nos merezca, es un campo plagado de ideologías e intereses individuales, por tanto no nos movemos en una problemática 
estrictamente técnica, aunque la teoría económica sobre la que se apoya (teoría económica neoclásica) así nos lo haga ver. Su funcionamiento es algo muy complejo e implica un sin fin de connotaciones que difícilmente pueden manejarse con facilidad. Al mismo tiempo, como acabamos de mencionar nos es imposible pensar en el ámbito financiero como algo emancipado del sistema económico capitalista. Esto conlleva una consecuencia transcendental, si queremos buscar soluciones efectivas a las crisis periódicas que acompañan a la expansión de las finanzas, no podemos culpabilizar de la crisis únicamente a factores relacionados con el sistema financiero, como: mala regulación, concesión de hipotecas de alto riesgo, movimientos de tipos de interés por parte de la Reserva Federal Estadounidense y los bancos centrales, etc. De hacerlo, estaríamos cometiendo un grave error que acarrea dos problemas principales:

- Encubrir atrofias del modelo de crecimiento económico capitalista. Se vuelve a legitimar un sistema que está permanentemente en crisis para la mayor parte de las personas, como muestra el aumento continuado de las desigualdades sociales, el incremento en la polarización de la riqueza, la pobreza extrema, explotación infantil y el aumento en la precariedad laboral, por poner sólo algunos ejemplos.

- Desviar las respuestas exclusivamente hacia un foco de problemas -el sistema financiero-, cuando realmente es sólo la punta del iceberg. El ejemplo más claro de esta orientación se observa en la declaración final redactada tras la cumbre del G-20 celebrada en Washington el 15 de Noviembre del 2008. En este informe se pone de manifiesto que las causas de la crisis radican en irregularidades cometidas en el sector financiero (normas deficientes frente al control de riesgos, prácticas poco fiables, etc.), esto hace que las medidas acordadas se dirijan exclusivamente a solventarlas y en ningún momento se cuestione el modelo de crecimiento del capitalismo, que es donde realmente radican los verdaderos problemas. Como estamos observando, estas medidas están "surtiendo efecto" en muchos países, pero no cabe duda de que esta mejora es sólo coyuntural y para con las cifras económicas, no suponiendo avance alguno sobre las lacras reales del sistema mundo en que nos encontramos (incremento de la pobreza mundial y las desigualdades sociales, polarización de la riqueza, etc.).

La interdependencia del mundo actual pone de manifiesto la incapacidad individual de cualquier Estado para aportar soluciones reales, haciendo imprescindible la acción colectiva del mayor número posible de países. Puede que suene utópico, pero el camino a seguir 
empezaría por la adopción de un Nuevo Orden Económico Mundial, cimentado bajo principios e instituciones diferentes: más democráticas, más participativas y más justas.

\section{BIBLIOGRAFÍA}

AGLIETTA, Michael (2000) "La globalización financiera", Finanzas, inversión y crecimiento, 59, Mayo-Agosto, pp. 7-21.

- y Jean CARTELIER (2002) "Orden monetario de las economías de mercado", Cuadernos de Economía, XXI, 36, Bogotá, pp. 41-75.

AMIN, Samir (1998) El capitalismo en la era de la globalización. Barcelona: Paidós Ibérica.

- (2001; 2007) "Capitalismo, Imperialismo, Mundialización". Fernando LóPEZ CASTELLANO (comp.) Desarrollo: Crónica de un desafío permanente. Universidad de Granada.

ANGÉLOPOULOS, Angélos (1979) Desarrollo internacional. México, D.F.: Fondo de Cultura de México.

ARRIGHI, Giovanni $(1998 ; 2007)$ "La globalización, la soberanía estatal y la interminable acumulación del capital". Fernando LóPEZ CASTELLANO (comp.) Desarrollo: Crónica de un desafío permanente. Universidad de Granada.

- (2000) Caos y orden en el sistema-mundo moderno. Madrid: Akal.

BHAGWATI, Jagdish (2005) En defensa de la globalización: el rostro humano de un mundo global. Barcelona: Debate.

BOURDIEU, Pierre (1998) Contrafuegos. Barcelona: Anagrama.

- (2002) Las estructuras sociales de la Economía. Barcelona: Anagrama.

BRAUDEL, Fernand (1986) La dinámica del capitalismo. México, D.F.: Fondo de Cultura Económica.

BRUGUE TORRUELLA, Joaquim (1992) "Gobierno local y thatcherismo: redefinición de la política municipal británica entre 1979 Y 1990", Revista de Estudios Políticos, 77, Julio-Septiembre, pp. 285-302.

CHANG, Ha-Joon (2004) Retirar la escalera. La estrategia del desarrollo en perspectiva histórica. Madrid: IUDC y los libros de la catarata. 
CHESNAIS, Francois (2002) La globalización y sus crisis: interpretaciones desde la economía crítica. Madrid: Libros de la Catarata.

- y Dominique PHIL (2003) La Trampa de las finanzas mundiales: diagnósticos y remedios. Madrid: Akal.

DEUTSCH, Karl Wolfgang (1974) El análisis de las relaciones internacionales. Buenos Aires: Paidós.

FONDO MONETARIO INTERNACIONAL (2008) "Perspectivas de la economía mundial", Octubre.

- (2008) "Por una economía mundial para todos", Informe anual.

FRIEDMAN, Milton (1992) La economía monetarista. Barcelona: Gedisa.

GALBRAITH, John Kenneth (1991) Breve historia de la crisis financiera. Barcelona: Ariel.

GonzÁlez TABLAS, Ángel y Bibiana MEDIALDEA (2001) "Reflexión crítica sobre la Globalización financiera", Revista Ekonomiaz, 48, $3^{\circ}$ Cuatrimestre, pp. 58-91.

GramsCl, Antonio (1973) Americanismo y fordismo. Roma: Riuniti.

GUTIÉRREZ LóPEZ, Cristina y José Miguel FERNÁNDEZ FERNÁNDEZ (2006) "Evolución del proceso de regulación bancaria hasta Basilea-2: origen, características y posibles efectos", Pecvnia, 2, pp. 23-66.

G-20 (2008) Declaración final Cumbre Washington. 15 de noviembre.

HARVEY, David (1998) La condición de la posmodernidad. Buenos Aires: Ed. Amorrorto.

HAYEK, Friedrich August (2006) Los fundamentos de la libertad. Madrid: Unión Editorial.

HUGHET SANTOS, Montserrat (2005) "Reagan y el neoliberalismo europeo". José María Beneyto, Guillermo A. PÉREz SÁnChez y Ricardo M. MARTín DE LA GUARDIA (coords.) Europa y Estados Unidos: una historia de la relación atlántica en los últimos cien años. Madrid: Biblioteca nueva, pp. 247-260.

KEYNES, John (1948) La teoría general del empleo, el interés y el dinero. México, D.F.: Fondo de Cultura Económica.

KIndLeberger, Charles Poor (1991) Manías, pánicos y cracs. Historia de las crisis financieras. Barcelona: Ariel.

KRUGMAN, Paúl R. (2004) El gran engaño: ineficacia y deshonestidad: Estados Unidos ante el siglo XXI. Barcelona: Crítica. 
LICHTENSZTEJN, Samuel y Mónica BAER (1986) Fondo monetario internacional y Banco Mundial: estrategias y políticas del poder financiero. Buenos Aires: Centro de Estudios Transnacionales.

MARAZZI, Christian (2003) El sitio de mis calcetines. Madrid: Akal.

PIÑERO, Julio Fernando (2004) "El modo de desarrollo Fordista-Keynesiano: Características, Crisis y reestructuración del capitalismo", Eumes Contribuciones a la Economía, junio, pp. 1-18.

RAJAMOORTHY, T. (2004) "Bretton Woods y el triunfo de la hegemonía de Estados Unidos", Revista del Sur, 155-156, Septiembre-Octubre [http://www.redtercermundo.org.uy/revista_del_sur/texto_completo. php?id=2588].

SMITH, Adam (1996) La riqueza de las naciones. Madrid: Pirámide.

StIGLITZ, Joseph E. (2003) Los felices 90: la semilla de la destrucción. Madrid: Taurus.

- (2004) El malestar en la globalización. Madrid: Taurus.

- (2006) Cómo hacer que funcione la globalización. Madrid: Taurus.

TORRES, Juan (2005) Toma el dinero y corre. La globalización neoliberal del dinero y las finanzas. Barcelona: Icaria.

WALLERSTEIN, Inmanuel (1995; 2007) "La reestructuración capitalista y el sistema mundo". Fernando LóPEZ CASTELLANO (comp.) Desarrollo: Crónica de un desafío permanente. Universidad de Granada.

- (1999) El futuro de la civilización capitalista. Barcelona: Icaria. 